\title{
Management of IFI in Febrile Neutropenic Patients: A Case of Invasive Aspergillosis Treated with Liposomal Amphotericin B
}

\author{
Omur G. SEVINDIK, Serife M. SOLMAZ, Celal ACAR, Inci ALACACIOGLU, Ozden PISKIN, \\ Güner H. OZSAN, Bulent UNDAR, Fatih DEMIRKAN, M. Ali OZCAN
}

Department of Hematology, Dokuz Eylul University Faculty of Medicine, Izmir, TURKEY

TO THE EDITOR:

A 70 years old female patient who was previously diagnosed with relapsed chronic lymphocytic leukemia was referred to our clinic with complaints of fever, dyspnea and cough. The blood count and peripheral blood smear revealed neutropenia and she was hospitalized with the diagnosis of febrile neutropenia. Patient was already on the second month of alemtuzumab therapy which was known to cause serious immunosupression. Physical examination revealed bilateral inspiratory crackles. With presumptive diagnosis of febrile neutropenia and bacterial pneumonia empirical extended spectrum antibiotic combination with antipseudomonal activity was started (piperacillin-tazobactam and ciprofloxacin). She was still febrile on the 3rd day of antibiotics and aspergillus galactomannan was 0,70 (positive). Considering that piperacilin-tazobactam may cause false positive galctomannan results ${ }^{1}$, in order to eliminate a possible pulmonary aspergillosis, HRCT was performed. HRCT showed some scarce milimetric nodular consolidations with irregular margins and were surrounded by a halo with ground glass opacification (Figure 1A-BC). Liposomal amphotericin B treatment was initi- ated depending on the positive galactomannan and halo signs on HRCT which were thought to be related to an invasive aspergillus infection in an immunocompromized patient. ${ }^{2}$ In the meanwhile, bronchoscopic evaluation was requested to clarify and isolate the possible microorganism. Bronchoscopy was applied with no major complication and bronchoalveolar galactomannan was found to be 2.40 (positive). The fungal culture of bronchoalveolar lavage revealed both aspergillus fumigatus $(200 \mathrm{cfu} / \mathrm{ml})$ and aspergillus flavus $(1000 \mathrm{cfu} / \mathrm{ml})$ which were known to be sensitive to liposomal amphotericin B therapy. ${ }^{3}$ At the fourth day of liposomal amphotericin B treatment with appropriate dosage and administration, the fever subsided and the symptoms related to pneumonia regressed. After the third week of antifungal therapy, complete radiological response was achieved and liposomal amphotericin B was stopped at 4th week. In this immunocompromised patient, pulmonary aspergillosis, which occured after highly immunosupressive therapy with alemtuzumab, was successfully treated with appropriate antifungal therapy and did not relapse. 


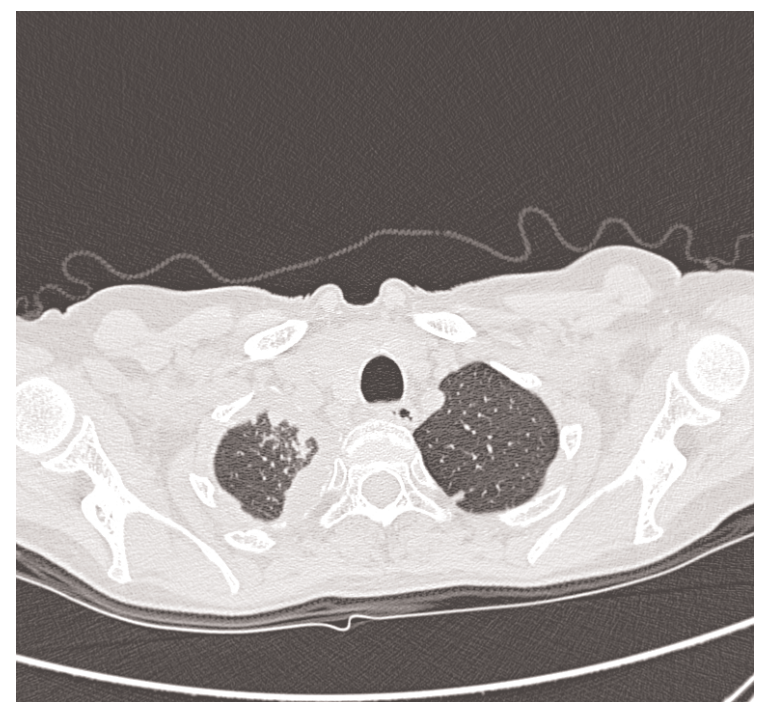

Figure 1A. Nodular consolidations with pleural effusion.

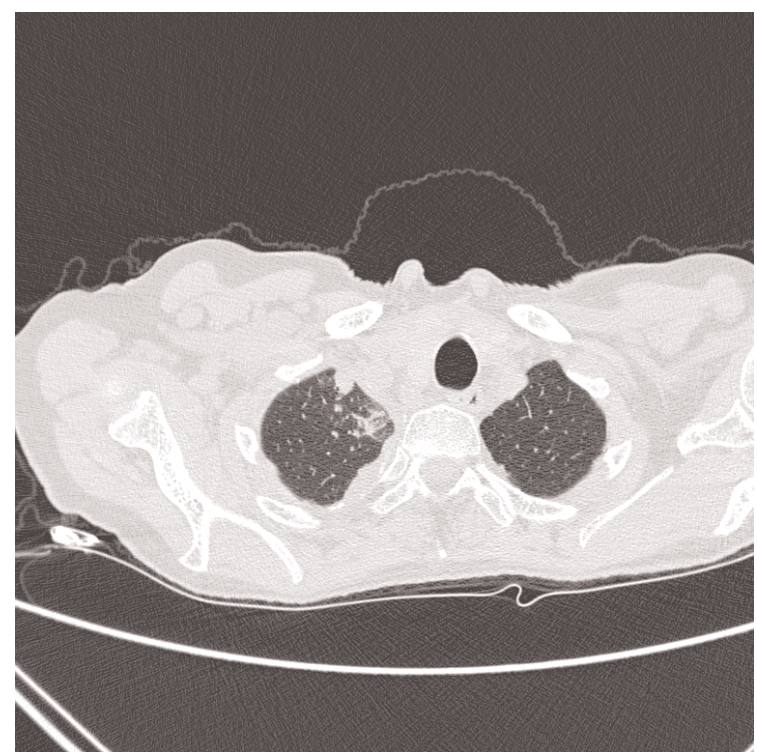

Figure 1C. Nodular consolidations, one with regular margins and the other with irregular margins and a halo with ground glass opacification.

\section{REFERENCES}

1. Boonsarngsuk V, Niyompattama A, Teosirimongkol C, Sriwanichrak K. False-positive serum and bronchoalveolar lavage Aspergillus galactomannan assays caused by different antibiotics. Scand J Infect Dis 42: 461-468, 2010.

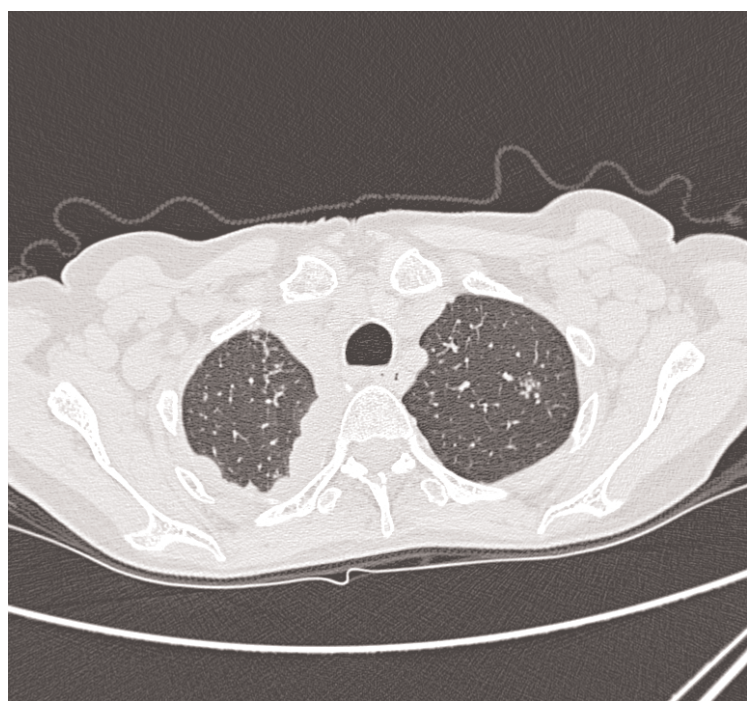

Figure 1B. Scarce milimetric nodular consolidations with irregular margins.

2. Cornely OA, Maertens J, Bresnik M, et al. Liposomal amphotericin B as initial therapy for invasive mold infection: a randomized trial comparing a high-loading dose regimen with standard dosing (AmBiLoad trial). Clin Infect Dis 44: 1289-1297, 2007.

3. Lass-Flörl C, Mayr A, Perkhofer S, et al. Activities of antifungal agents against yeasts and filamentous fungi: assessment according to the methodology of the European Committee on Antimicrobial Susceptibility Testing. Antimicrob. Agents Chemother 52: 36373641, 2008.

\section{Correspondence}

Dr. Mehmet Ali ÖZCAN

Dokuz Eylül Üniversitesi Tıp Fakültesi Hastanesi Hematoloji Anabilim Dalı

Mithatpaşa Cd

35340, İnciralt, IZMIR / TURKEY

\section{Tel: (+90.532) 3353721}

Fax: (+90.232) 2599723

m-mail: mehmet.ozcan@deu.edu.tr 